\title{
Shorter GT repeat polymorphism in the heme oxygenase-1 gene promoter has protective effect on ischemic stroke in dyslipidemia patients
}

\author{
Chyi-Huey Bai1,2, Jiunn-Rong Chen³, Hou-Chang Chiu4 ${ }^{4}$,Chia-Chi Chou 5 , Lee-Young Chau*+6 and Wen-Harn Pan*t6
}

\begin{abstract}
Background: The microsatellite polymorphism of heme oxygenase (HO)-1 gene promoter has been shown to be associated with the susceptibility to ischemic event, including coronary artery disease (CAD), myocardial infarction, and peripheral vascular disease. We aimed to examine whether the length of (GT) ${ }_{n}$ repeats in $\mathrm{HO}-1$ gene promoter is associated with ischemic stroke in people with CAD risk factors, especially low level of HDL.

Methods: A total of 183 consecutive firstever ischemic stroke inpatients and 164 non-stroke patients were screened for the length of (GT) repeats in $\mathrm{HO}-1$ promoter. The long $(\mathrm{L})$ and short $(\mathrm{S})$ genotype are defined as the averaged repeat number $>26$ and $\leqq 26$, respectively.

Results: Stroke patients tended to have more proportions of hypertension, diabetics and genotype L, than those of genotype $\mathrm{S}$. Patients with genotype L of HO-1 gene promoter have higher stroke risk in comparison with genotype $S$ especially in dyslipidemia individuals. The significant differences on stroke risk in multivariate odds ratios were found especially in people with low HDL-C levels.

Conclusions: Subjects carrying longer (GT) ${ }_{n}$ repeats in $\mathrm{HO}^{-1}$ gene promoter may have greater susceptibility to develop cerebral ischemic only in the presence of low $\mathrm{HDL}-\mathrm{C}$, suggesting the protective effects in $\mathrm{HO}-1$ genotype $\mathrm{S}$ in the process of ischemic stroke, particularly in subjects with poor HDL-C status.
\end{abstract}

\section{Background}

Heme oxygenese (HO) is a rate-limiting enzyme in heme degradation, leading to the liberation of free iron, carbon monoxide (CO) and biliverdin[1]. HO-1, one of HO isoforms. is a stress-responsive protein induced by various oxidative agents[1,2]. Over past few years, numerous studies have revealed the important function of HO-1 in cardiology by aspects such as inflammation, antioxidant function, apoptosis, hypoxia and ischemia/reperfusion injury, and angiogenesis [3].

HO-1 as a cytoprotective defense mechanism against oxidative insults is through the antioxidant activities of biliverdin and its metabolite, bilirubin [4], as well as the antiimflammatory, antifibrinolytic and vasodilative actions of $\mathrm{CO}[2,5,6]$. HO- 1 also is up-regulated during cerebral ischemia [7-10], in relation to the severity of brain injury [11]

\footnotetext{
*Correspondence: lyc@ibms.sinica.edu.tw, pan@ibms.sinica.edu.tw Institutes of Biomedical Sciences, Academia Sinica, Taipei, Taiwan + Contributed equally
}

or aneurysms [7], and also exert a protective effect on neuronal cell against oxidative stress $[12,13]$. The first case of HO-1 deficiency in human was identified in 1999 [14], the patient suffered persistent hemolytic anemia and abnormal coagulation/fibrinolysis system associated with elevated thrombomodulin and von Willebrand factor, indicating persistent vascular injury. Two studies focused HO-1 mocroglia/macrophage and cerebrovascular disease speculated the prolong expression of $\mathrm{HO}-1$ in traumatic brain injury, cerebral infarction and aneurysms [7,10]. HO-1 is also induced in atherosclerotic lesions of human and experimental animals, and has a protective role in the blood vessel wall during atherogenesis $[15,16]$. Overexpression of HO-1 in arterial walls reduces lesion formation as well as intimal hyperplasia subsequent to vascular injury, supporting its vasoprotective function [17-19]. Several positive physiological effects exerted by HO-1 as anti-inflammatory and cytoproective functions in cardiovascular and peripheral vascular disease [20]. 
The human HO-1 gene is mapped on chromosome $22 \mathrm{q} 12$ with a $(\mathrm{GT})_{\mathrm{n}}$ dinucleotide repeat polymorphism in the proximal promoter region [21,22]. It has been shown that the $(\mathrm{GT})_{\mathrm{n}}$ repeat is highly polymorphic and modulates the transcriptional activity of HO-1 gene $[23,24]$. Promoter containing longer $(\mathrm{GT})_{\mathrm{n}}$ repeats has lower transcriptional activity in vascular cells [24]. We and others have reported that human subjects carrying longer $(\mathrm{GT})_{\mathrm{n}}$ repeats have increased susceptibility to the development of coronary artery disease [4,24,25], post-angioplasty restenosis [26-28] and advanced peripheral artery disease [29], indicating that HO-1 promoter polymorphism is likely to act as an candidate in the genetic determinant involved in vascular disease.

Ischemic stroke is a common disease with high mortality rate in populations [30], earlier studies have revealed the family history as an independent risk factor, suggesting the involvement of genetic components in the pathogenesis of ischemic stroke [31]. Ischemic stroke shares many common risk factors with other vascular disease, such as hypertension, diabetes, hyperlipidemia and smoking. Although the neuroprotective effect and the ability of reduced infarct size of HO-1 have been shown [32], the only study focused on recurrent and first ischemic cerebrovascular events still not reported a significant association between $\mathrm{HO}-1$ promoter polymorphism and stroke [3]. In view of the vital role of $\mathrm{HO}-1$ in vascular protection, here we aimed, especially in those stroke patients with no history of cerebro- or cardiovascular events, to examine the association between the risk of ischemic stroke and the length of the $(\mathrm{GT})_{\mathrm{n}}$ repeats of the HO-1 gene promoter under several vascular conditions: hypertension, diabetes, lipids abnormality and smoking. We also aimed to explore the interaction of the HO-1 genotype and above risk factors on ischemic stroke.

\section{Methods}

\section{Participants}

A total of 183 consecutively hospitalized first-ever ischemic stroke (IS) inpatients and 164 non-stroke (NS) outpatients were recruited from neurological ward and clinics of Shin Kong WHS Memorial Hospital in Taipei city from mar 1996 to Dec 1999. These first-ever inpatients were recruited within the first $48 \mathrm{~h}(20.3 \pm 14.9 \mathrm{~h})$ of the stroke onset. Inclusion criteria for IS patients were: (a) IS patients admitted within 48 hours of onset; (b) age greater than 40 years; (c) no prior history of stroke and myocardial infarction. NS outpatients are those with complaints of nonspecific symptoms such as peripheral vestibulopathy, radiculopathy, low back pain, insomnia, Parkinson's disease, myalgia, arthralgia, muscle pain, muscle stiffness, or headache. Neurologist had confirmed that these NS patients had no evidence of stroke and myocardial infarction. The controls were enrolled during the same recruitment periods with cases, and the recruitment was performed blindly with respect to patient's clinical data and HO-1 genotypes. The study was approved by Ethics Committee/Institutional Review Board (EC/IRB) of the hospital, and informed consent was obtained from every subject.

\section{Data Collection and measurement}

Information on age, sex, residential area, and risk factors of stroke was obtained via interview within 3 to 7 days of admission. Diagnosis of stroke and stroke subtype of each subject was confirmed by a single neurologist (the second author) based on data from clinical assessment and neurological images such as computerized tomography (CT), and other studied tests. Cerebral infarction was defined as a focal neurological deficit of sudden onset that persisted beyond 24 hours in surviving patients with indication of the presence of infarction and the absence of hemorrhage, which was documented by brain CT or by MRI. Information on medication and on chronic diseases such as hypertension, diabetes mellitus, coronary heart disease, left ventricular hypertrophy ( $\mathrm{LVH})$, atrial fibrillation (AF), and other related diseases were transcribed from various types of medical records including medical charts, lab reports, nursing diaries and reports of ECG, chest X-ray, and echocardiogram.

Blood samples of the patients were drawn after at least an 8 -hour over-night fast. Fasting venous blood was drawn into two $5 \mathrm{cc}$ heparinized tubes. Plasma and buffy coat were prepared immediately after drawing and stored at $-70^{\circ} \mathrm{C}$. Heparinized plasma was used to measure total cholesterol (TC) and high-density lipoprotein cholesterol (HDL-C) (Lieberman-Burchard method), triglyceride (Bucolo method), and glucose (Keston method), with a Hitachi autoanalyzer (Hitachi 7250, Hitachi, Japan). Low-density lipoprotein cholesterol (LDL-C) value was calculated from levels of TC, triglyceride and HDL-C[33]. The coefficient of variation of 65 duplicated samples was $2.2 \%$ for TC, $3.1 \%$ for triglyceride, $2.8 \%$ for HDL-C and $2.5 \%$ for glucose. The stroke patients were followed from admission to 3 months later. In this study, we analyzed the data of the blood after 3 months of onset in stroke patients to ensure that blood levels were stabilized.

Hypertension was defined by systolic/diastolic blood pressure $\geqq 140 / 90 \mathrm{~mm} \mathrm{Hg}$ or by receiving antihypertensive therapy. The measurement of blood pressure from left arm was obtained and used. Diabetes was defined by fasting plasma glucose $\geqq 126 \mathrm{mg} / \mathrm{dL}$ or by taking hypoglycemic medication. Patients with hypercholesterolemia, hypertriglyceridemia, high LDL-C level and low HDL-C level were defined by total cholesterol level $\geqq 240 \mathrm{mg} / \mathrm{dL}$, triglyceride level $\geqq 200 \mathrm{mg} / \mathrm{dL}$, TC/HDL-C ratio $\geqq 5$, LDL-C level $\geqq 130 \mathrm{mg} / \mathrm{dL}$, HDL-C level $<40 \mathrm{mg} / \mathrm{dL}$ (for men) $/<50 \mathrm{mg} /$ $\mathrm{dL}$ (for women), respectively. Obesity was defined as body 
mass index $\geqq 27$. Ever-smoker was those subjects with current or past smoking habits.

An extracranial carotid duplex ultrasound machine (SONO 1000; Hewlett-Packard Company; USA), with a transducer frequency of $7.5 \mathrm{~Hz}$ and color frequency of 5.4 $\mathrm{Hz}$, was used. A standardized protocol was established. The near and far walls of the left and right proximal common carotid artery (CCA), distal CCA, proximal external carotid artery, proximal internal carotid artery, and carotid bifurcation were examined by B-mode duplex scanning. The degree of plaque was graded as follows: $0=$ no plaque; $1=$ one small plaque $<30 \%$ of the vessel diameter; $2=$ one medium plaque between $30 \%$ and $50 \%$ of the vessel diameter or multiple small plaques; $3=$ one large plaque $>50 \%$ of the vessel diameter or multiple plaques with at least one medium plaque. The grades in each segment of all carotid arteries were added to create a summary plaque score corresponding to the extent of carotid atherosclerosis.

\section{Analysis of Length Variability of (GT)n Repeats in HO-1 Gene Promoter}

Genomic DNAs were extracted from storaged leukocytes by conventional procedures. The 5'-flanking region containing $(\mathrm{GT})_{\mathrm{n}}$ repeats of the HO-1 gene was amplified by PCR with a FAM-labeled sense primer, 5'-AGAGCCTGCAGCTTCTCAGA-3', and an antisense primer, 5'ACAAAGTCTGGCCATAGGAC-3', according to the published procedure [34]. The PCR products were mixed together with GenoType ${ }^{\mathrm{TM}}$ TAMRA DNA ladder (size range 50-500 bp) (GibcoBRL) and analyzed with automated DNA sequencer (ABI Prism ${ }^{\text {TM }} 377$ ). Each size of the $(\mathrm{GT})_{\mathrm{n}}$ repeat was calculated using the GeneScan Analysis software (PE Applied Biosystems).

\section{Statistical analysis}

The distribution of the numbers of $(\mathrm{GT})_{\mathrm{n}}$ repeats of two DNA strands were studied, and the frequency of repeats in patients was plotted. Assuming a co-dominant (additive) trait model, HO-1 genotypes were defined by the averaged length of $(\mathrm{GT})_{\mathrm{n}}$ repeats. Averaged length of $(\mathrm{GT})_{\mathrm{n}}$ repeats of the HO-1 gene promoter was calculated for each patient.

Age was expressed as mean \pm SD and compared by Student's $t$ tests. Chi-square test was used to examine whether CAD risk factors (hypertension, diabetes, all lipids abnormalities, and smoking habits) and some other characteristics differed between IS patients and NS controls. Chisquare test was also used to compare frequency of genotype $\mathrm{S}$ and L between IS patients and NS controls in all subjects or in subgroups stratified by above risk factors. However, only the figure on HDL-C was shown. The associations between stroke status and HO-1 genotypes were examined by stratifying on stroke and cardiovascular (CVD) risk factors. The risk of odds ratio (OR) was showed after adjusted the following factors: age, sex, hypertension, diabetes, smoking habits, lipid abnormalities, obesity, or plaque score if necessary. Two sides $\mathrm{p}$ value was calculated, and significant level was accepted at $P<0.05$. Statistical calculations were performed using SAS software package (version 9.1).

\section{Results}

The length of the $(\mathrm{GT})_{\mathrm{n}}$ repeats in the human HO-1 gene promoter region ranged from 15 to 39 , as shown in figure 1 . The distribution had two peaks at $(\mathrm{GT})_{23}$ and $(\mathrm{GT})_{30}$, respectively. The averaged length of the $(\mathrm{GT})_{\mathrm{n}}$ repeats had similar distribution, but they ranged from 15 to 35 with peaks at 27 and 30. Therefore, we defined genotype short (S) for those with averaged length $\leqq 26$ GT repeats, and genotype long (L) for those with length of $>26$ GT repeats, which included around 70 percent of patients.

Stroke patients were significantly older (mean aged 65.5 \pm 12.2 versus $62.8 \pm 11.5$ in controls, $\mathrm{p}=0.0465)$. They also had significantly greater proportion of diabetes, hypertension, LDL-C, lowered HDL-C level, obesity, and higher plaque score than the controls (Table 1). Additionally, stroke patients tended to have more males, more eversmokers, more lipids abnormalities and more genotype L than controls. However, no significant differences were found between IS and NS patients.

Table 2 shows the distribution of genotypes of HO- 1 gene promoter by several cardiovascular risk factors, respectively, in stroke patients and in non-stroke controls. A higher proportion of genotype L was observed in stroke patients than in non-stroke patients in those with lowered HDL-C $(\mathrm{p}=0.0056)$, normal TC level $(\mathrm{p}=0.0490)$, and normal LDL-C level $(\mathrm{p}=0.0270)$, so was in those with high TC/HDL-C ratio with borderline significant $(\mathrm{p}=0.0747)$. Stroke patients tended to have higher frequency of genotype L than non-stroke patients in patients with diabetes, hypertension, hyperlipidemia, ever-smoking habit and high carotid plaque score, respectively; but these were not statistically significant (Table 2). In addition, stratified analysis further showed that diabetics tended to have higher proportion of genotype $\mathrm{L}$ than non-diabetics. But the significance was only shown for stroke patients $(\mathrm{p}=0.0389)$.

According the results of table 2, we next examined whether the genotype of the human HO-1 gene promoter was associated with ischemic stroke under different lipids conditions: normal TC level and LDL-C level as well as abnormal HDL-C level (Table 3). In analysis of these subgroup, only the significant adjusted ORs were showed in those with lowered HDL-C levels (Model I and II OR \& p value, 2.07, 0.0303 and 2.02, 0.0405, respectively). The multivariate ORs were not significant in the analyses of TC and LDL-C. For describing the interaction of HDL-C and genotypes, figure 2 shows the age- and sex-adjusted OR on stroke risk for HO-1 gene genotypes by the HDL-C status. Patients of genotype L tended to have larger ORs than those 


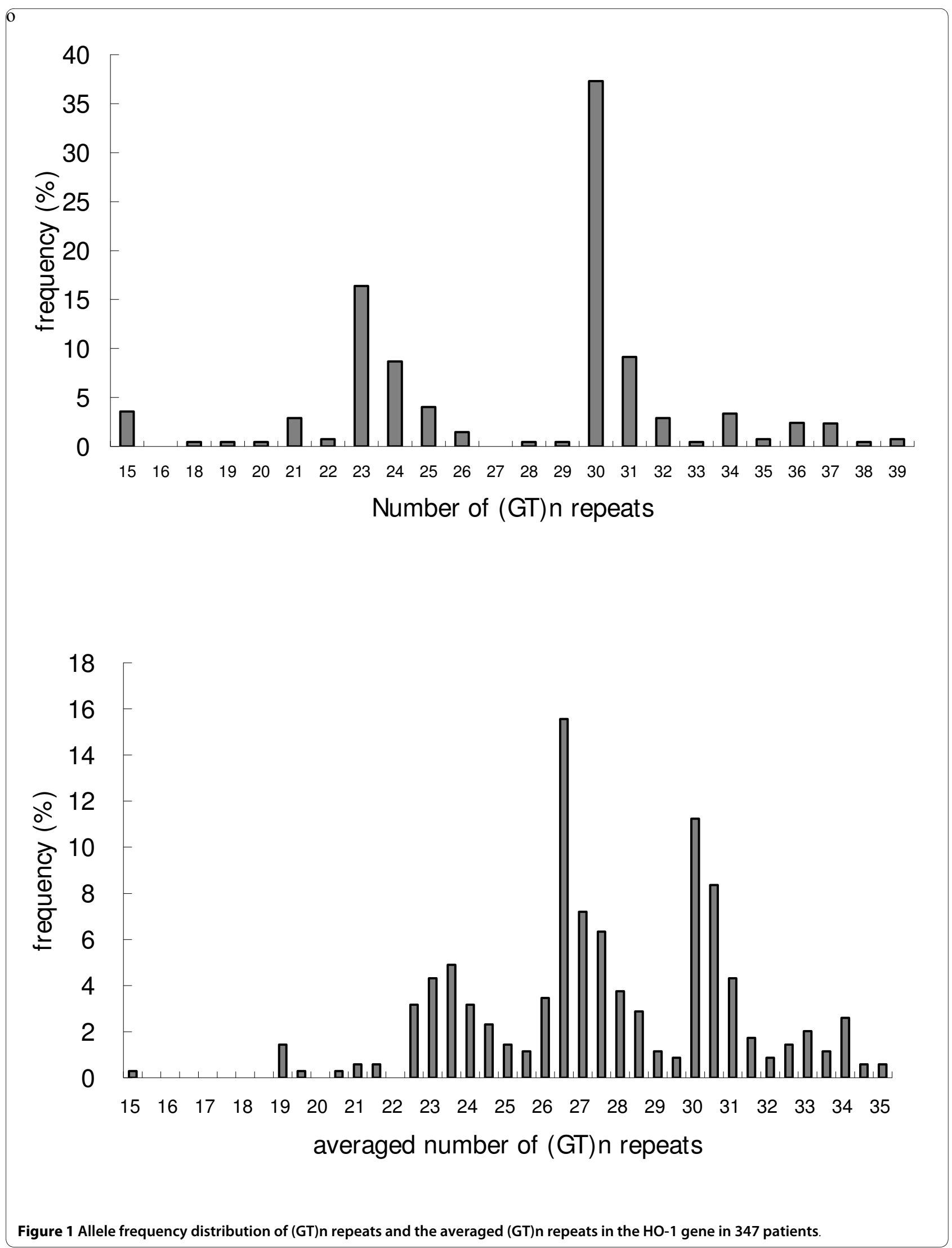


Table 1: Distribution of CVD risk factor status in stroke patients and their controls

\begin{tabular}{|c|c|c|c|c|}
\hline & & $\begin{array}{c}\text { Stroke patients }(\mathrm{n}= \\
183)\end{array}$ & $\begin{array}{l}\text { Non-stroke patients } \\
\quad(n=164)\end{array}$ & \\
\hline Variables & & N (\%) & N (\%) & $\mathbf{P}$ \\
\hline Gender & Male & $114(62.3)$ & $87(53.1)$ & 0.0815 \\
\hline Diabetes & $Y_{e s}^{\S}$ & $64(35.0)$ & $19(11.6)$ & $<0.0001^{* * *}$ \\
\hline Hypertension & Yes\& & $151(82.5)$ & $90(54.9)$ & $<0.0001^{* * *}$ \\
\hline TC & $\geqq 240 \mathrm{mg} / \mathrm{dL}^{+}$ & $26(14.2)$ & $32(19.5)$ & 0.1861 \\
\hline Triglyceride & $\geqq 200 \mathrm{mg} / \mathrm{dL}^{+}$ & $44(24.0)$ & $38(23.2)$ & 0.8480 \\
\hline LDL-C & $\geqq 130 \mathrm{mg} / \mathrm{dL}^{+}$ & $52(28.4)$ & $66(40.2)$ & $0.0202^{*}$ \\
\hline HDL-C & $\begin{array}{l}<40 / 50 \mathrm{mg} / \mathrm{dL} \text { in male/ } \\
\text { female }\end{array}$ & $131(71.6)$ & $68(41.5)$ & $0.0001^{* * *}$ \\
\hline $\mathrm{TC} / \mathrm{HDL}-\mathrm{C}$ ratio & $\geqq 5^{+}$ & $66(36.1)$ & $58(35.4)$ & 0.8920 \\
\hline Smoker & Ever (current/past) & $73(39.9)$ & $47(28.7)$ & 0.0804 \\
\hline BMI & $\geqq 27$ & $23(12.6)$ & $40(24.4)$ & $0.0043^{* *}$ \\
\hline Plaque score & $\geqq 3$ & $83(45.3)$ & $43(26.2)$ & $0.0002^{* * *}$ \\
\hline Genotype & $\mathrm{L}:>26$ GT repeats & $138(75.4)$ & $114(69.5)$ & 0.4262 \\
\hline
\end{tabular}

${ }^{\S}$ fasting blood glucose $\geqq 126 \mathrm{mg} / \mathrm{dL}$ or on DM medication. ${ }^{\& S B P} \geqq 140 \mathrm{mmHg}$ or DBP $\geqq 90 \mathrm{mmHg}$ or on anti-hypertension medication. ${ }^{+}$ included those patients with related medication. TC: total cholesterol; HDL-C: high-density lipoprotein cholesterol; LDL-C: low-density lipoprotein cholesterol; BMl: body mass index. $\mathrm{P}$ : the $\mathrm{p}$ value from chi-square test between stroke and non-stroke patients. Genotype; the length of GT repeats in HO-1 gene promoter. ${ }^{*}: p<0.05$; $^{* *}: \mathrm{p}<0.01{ }^{* * *}: \mathrm{p}<0.001$

f genotype $\mathrm{S}$ in people carrying lowered HDL-C status (genotype L vs S in OR: 3.20 vs 1.44 in low HDL-C group), as well as other CVD risk factors (detailed data not shown). Similar trend was found but with no statistical significance. In addition, we also examined the increased effects for genotype $\mathrm{L}$ in comparing with $\mathrm{S}$ in each high risk factor profile group. In those with low HDL-C, subjects with genotype L had significantly greater stroke risk than those with genotype $S(p=0.007)$.

\section{Discussion}

Our study revealed that shorter HO-1 promoter genotype has the protective effect on ischemic stroke, especially in the patients with lower HDL-C levels. The effects and interactions were demonstrated in univariate and multivariate models for all subjects, and the protective gene effect appeared in the stratified high risk group, not in the low risk group. The significant increases of genotype $\mathrm{L}$ than $\mathrm{S}$ indicated the protective genetic effects of shorter HO-1 gene repeats seem work up well in high risk group like low HDL-C level, and the risk was decreased to the level near the low risk group like appropriate HDL-C level. All of patients in our study had no prior CAD or stroke, so our observation was not confounded by selection bias, such as survivor for severe disease. It is less considered in previous studies.

Interestingly, we also described more risk effects of genotype L on stroke in those with normal TC or LDL-C levels than those of genotype $\mathrm{S}$, although the effect was no longer present in multivariate analysis. Before our study, one study reported shorter repeats in $\mathrm{HO}-1$ gene exerted a protective effect on the development of ischemic cerebrovascular events definitely in patients without hypercholesterolemia [3]. The finding was similar with that in our study, but they did not include HDL-C measure. In summary of our findings, the protective effect of HO-1 genotype on ischemic stroke depended on the presence of lipid conditions, that is, the levels of HDL-C, it may explain the controversial findings in the literatures.

Similar as the previous CAD studies, we did not find the significant difference of averaged $(\mathrm{GT})_{\mathrm{n}}$ repeats in HO-1 gene promoter between IS and NS patients. Instead, the lengths of $(\mathrm{GT})_{\mathrm{n}}$ repeat seem associated with the ischemic stroke status only in those individuals with lowered HDL-C level from our observation and some previous studies. Chen 
Table 2: Distribution of genotype of HO-1 gene promoter by risk factor status in stroke patients and their controls

\begin{tabular}{|c|c|c|c|c|c|c|}
\hline \multirow[b]{2}{*}{ Variables } & \multirow[b]{2}{*}{ Groups } & \multicolumn{2}{|c|}{ Stroke patients $(n=183)$} & \multicolumn{2}{|c|}{ Non-Stroke patients $(n=164)$} & \multirow[b]{2}{*}{$\mathbf{P}$} \\
\hline & & $\mathbf{s}$ & $\mathbf{L}$ & $\mathbf{s}$ & $\mathbf{L}$ & \\
\hline All subjects & & $45(24.6)$ & $138(75.4)$ & $50(30.5)$ & $114(69.5)$ & 0.4262 \\
\hline \multirow[t]{2}{*}{ Hypertension\& } & Yes & $37(24.5)$ & $114(35.5)$ & $26(28.9)$ & $64(71.1)$ & 0.4535 \\
\hline & No & $8(25.0)$ & $24(75.0)$ & $24(32.4)$ & $50(67.6)$ & 0.4441 \\
\hline \multirow[t]{2}{*}{ Diabetes * } & Yes & $10(15.6)$ & $54(84.4)$ & $4(21.1)$ & $15(79.0)$ & 0.8531 \\
\hline & None & $35(29.4)$ & $84(70.6)$ & $46(31.7)$ & $99(68.3)$ & 0.8824 \\
\hline \multirow[t]{2}{*}{$\mathrm{TC}$} & $\geqq 240 \mathrm{mg} / \mathrm{dL}^{+}$ & $9(34.6)$ & $17(65.4)$ & $6(18.8)$ & $26(81.3)$ & 0.2310 \\
\hline & Otherwise & $36(22.9)$ & $121(77.1)$ & $44(33.3)$ & $88(66.7)$ & $0.0490 *$ \\
\hline \multirow[t]{2}{*}{ Triglyceride } & $\geqq 200 \mathrm{mg} / \mathrm{dL}^{+}$ & $11(25.0)$ & $33(75.0)$ & $13(34.2)$ & $25(65.8)$ & 0.4664 \\
\hline & Otherwise & $34(24.5)$ & $105(75.5)$ & $37(29.4)$ & $89(70.6)$ & 0.3680 \\
\hline \multirow[t]{2}{*}{ LDL-C } & $\geqq 130 \mathrm{mg} / \mathrm{dL}^{+}$ & $15(28.9)$ & $37(71.2)$ & $14(21.2)$ & $52(78.8)$ & 0.3389 \\
\hline & Otherwise & $30(22.9)$ & $101(77.1)$ & $36(36.7)$ & $62(63.3)$ & 0.0270 * \\
\hline \multirow[t]{2}{*}{ HDL-C } & $\begin{array}{l}<40 / 50 \mathrm{mg} / \mathrm{dL} \\
\text { in male/ } \\
\text { female }\end{array}$ & $31(23.7)$ & $100(76.3)$ & $29(42.7)$ & $39(57.4)$ & $0.0056 * *$ \\
\hline & Otherwise & $14(26.9)$ & $38(73.1)$ & $21(21.9)$ & $75(78.1)$ & 0.4902 \\
\hline \multirow{2}{*}{$\begin{array}{l}\mathrm{TC} / \mathrm{HDL}-\mathrm{C} \\
\text { ratio }\end{array}$} & $\geqq 5^{+}$ & $14(21.2)$ & $52(78.8)$ & $21(36.2)$ & $37(63.8)$ & 0.0747 \\
\hline & Otherwise & $31(26.5)$ & $86(73.5)$ & $29(27.4)$ & $77(72.6)$ & 0.8758 \\
\hline \multirow[t]{2}{*}{ smoker } & Current + past & $17(23.3)$ & $56(76.7)$ & $12(25.5)$ & $35(74.5)$ & 0.8288 \\
\hline & Otherwise & $28(25.5)$ & $82(74.6)$ & $38(32.5)$ & $79(67.5)$ & 0.3060 \\
\hline \multirow[t]{2}{*}{ BMI } & $\geqq 27$ & $6(26.1)$ & $17(73.9)$ & $11(27.5)$ & $29(72.5)$ & 0.9032 \\
\hline & otherwise & $38(24.4)$ & $121(75.6)$ & $39(31.4)$ & $85(68.6)$ & 0.1851 \\
\hline \multirow[t]{2}{*}{ Plaque score } & $\geqq 3$ & $19(22.8)$ & $64(77.1)$ & $10(23.3)$ & $33(76.7)$ & 0.9633 \\
\hline & $<3$ & $26(26.0)$ & $74(74.0)$ & $40(33.1)$ & $81(66.9)$ & 0.3018 \\
\hline
\end{tabular}

$\mathrm{N}(\%)$. * fasting blood glucose $126 \mathrm{mg} / \mathrm{dL}$ or on DM medication. ${ }^{\&}$ SBP $140 \mathrm{mmHg}$ or DBP $90 \mathrm{mmHg}$ or on anti-hypertension medication. ${ }^{+}$ included those patients with related medication. TC: total cholesterol. HDL-C: high-density lipoprotein cholesterol; BMI: body mass index. P: the $p$ value from chi-square test comparing genotype $S$ and genotype $L$ between stroke and non-stroke patients in each CVD characteristic subgroup. $S$ and L genotypes: averaged (GT)n repeats 26 and $>26$, respectively. ${ }^{*}: p<0.05 ;{ }^{* *}: p<0.01 ;{ }^{* * *}: p<0.001$

and his coauthors have shown a protection of HO-1 genotype in diabetic CAD patients with at least 1 coronary narrowing $(>75 \%)$ and in restenosis patients after coronary stenting [24,35]. Another study has shown that the longer $(\mathrm{GT})_{\mathrm{n}}$ repeat in HO-1 gene promoter was related to CAD risk in diabetic and hypercholesterolemic patients [25]. Interestingly, in the other study, HO-1 gene exerted a protective effect on ischemic cerebrovascular events in patients with normal cholesterol level [3]. No effect of HO-1 genotype could be observed in total population, they only have been observed in high risk group or low risk group. It implies that long $(\mathrm{GT})_{\mathrm{n}}$ repeats alone may not be sufficient to cause diseases. But it may contribute to the development of the disease when certain conditions of enhanced oxidative stress coexist, including the abnormal composition of cholesterol levels in patients with normal total cholesterol levels.

Many studies reported that HO-1 gene involved in the mechanism against the development of atherosclerosis. Animal studies reported that products of $\mathrm{HO}$ pathway such 
Table 3: OR on stroke risk of genotype L compared to genotype $S$ in 3 subgroup analyses

\begin{tabular}{|c|c|c|c|c|c|c|c|}
\hline & & \multicolumn{3}{|c|}{ Model I } & \multicolumn{3}{|c|}{ Model II } \\
\hline & & OR & $(95 \% \mathrm{Cl})$ & $\mathbf{P}$ & OR & $(95 \% \mathrm{Cl})$ & $\mathbf{P}$ \\
\hline HDL-C & $\begin{array}{l}<40 / 50 \mathrm{mg} / \\
\mathrm{dL} \text { in male/ } \\
\text { female }\end{array}$ & 2.07 & $(1.07-4.01)$ & 0.0303 & 2.02 & $(1.01-4.02)$ & 0.0465 \\
\hline $\mathrm{TC}$ & $\begin{array}{l}<240 \mathrm{mg} / \\
\mathrm{dL}\end{array}$ & 1.62 & $(0.93-2.83)$ & 0.0918 & 1.63 & $(0.88-2.39)$ & 0.1182 \\
\hline LDL-C & $\begin{array}{l}<130 \mathrm{mg} / \\
\mathrm{dL}\end{array}$ & 1.91 & $(1.01-3.61)$ & 0.0480 & 1.63 & $(0.85-3.13)$ & 0.1435 \\
\hline
\end{tabular}

as bilirubin act as a significant protective factor for atherosclerosis[27]. The modulation of HO-1 gene expression in LDL-C receptor-deficient mice influence the progression of atherosclerosis [17], and mice treated with the HO-1 inducer exhibited reduced atherosclerotic lesion formation. Vascular proliferation was inhibited by transferring HO-1 gene[18]. These observations support that HO-1 functions as an intrinsic protective factor against atherosclerotic lesion formation and may be an anti-atherogenic role in vascular wall [15].

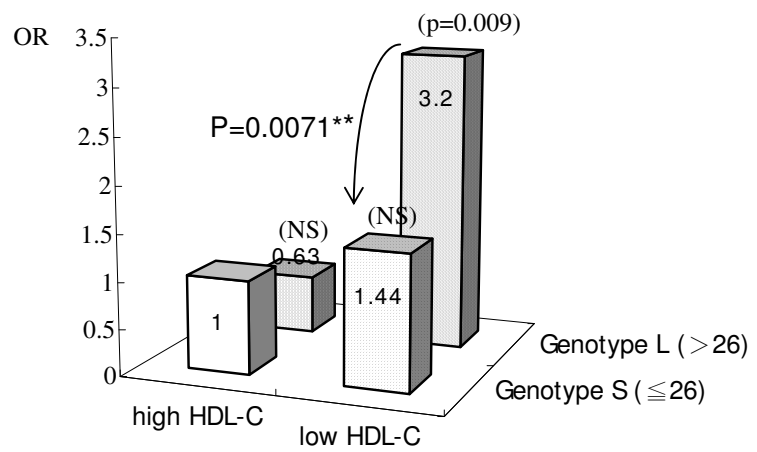

Figure 2 Age- and sex- adjusted odds ratio on stroke risk by HO1 genotypes by HDL-C level. Low HDL-C status is HDL-C level less than $40 \mathrm{mg} / \mathrm{dL}$ in men or $50 \mathrm{mg} / \mathrm{dL}$ in women. P-values in parenthesis were obtained for each subgroup comparing with the reference group (low risk and genotype $S$ ), and those $p$ values of $\geqq 0.05$ were not showed. Bold $p$ value near curved arrow was obtained for comparing risk of genotype $L$ with $S$ in the high risk factor profile group. NS: $p$ $\geqq 0.05$. $^{*}: p<0.05 .{ }^{* *}: p<0.01$. $^{* * *}: p<0.001$
Chen et al conducted a transient transfection experiment in rat aortic smooth muscle cells to show that longer $(\mathrm{GT})_{\mathrm{n}}$ repeats in HO-1 promoter decreased luciferase promoter activity, indicating decrease in gene transcription in vascular cells[24]. They also found that genotype L/L carriers are associated with higher extent of sever lipid peroxidation, supporting the genetic influence of HO-1 on oxidative stress. Lipid abnormalities like hypercholesterolemia correlate with enhanced oxidative stress. HDL-C acts as an antioxidant through its capability of inhibiting LDL-C oxidation, preventing the formation of lipid hydroperoxides $[36,37]$. Excessive oxidative stress was considered as a potential cause of the vascular disease and other complications in hyperglycemic patients [24,38]. S genotype in the HO-1 gene promoter may increase the induction of HO-1 by reactive oxygen species in patients with low HDL-C concentrations. The insufficient effect of anti-oxidative stress due to lower HDL-C levels may be reversed by $\mathrm{S}$ genotype in HO-1 gene promoter, thereby reducing the risk of cerebral ischemia.

In this study, the allelic frequency distribution of the lengths of $(\mathrm{GT})_{\mathrm{n}}$ repeats in the HO-1 promoter in recruited subjects (range from 15 to 39 ) was similar with that in the previous reports[23-25,34,35]. The previous studies defined $\mathrm{L}$ and $\mathrm{S}$ alleles first and constructed genotypes SS, SL, and LL to examine the disease risk. We demonstrated the results assuming co-dominant (additive) model and using averaged length of two alleles to define genotype $\mathrm{L}$ and $\mathrm{S}$, since the latter is more powerful and fits well the characteristics of complex model. We also obtained consistent results using the traditional (former) classification method: the age, sex $\&$ plaque score-adjusted OR of $2.26(\mathrm{p}=0.0263)$ and multivariate OR of $1.82(\mathrm{p}=0.0691)$ in those with lower HDL-C 
level while those carriers with homozygous S allele ( $\leqq 26$ GT repeats) as genotype SS compared with otherwise. The borderline significant findings on HO-1 genotype and cerebral ischemia were found in those with low HDL-C level or in those with high TC/HDL-C ratio. Therefore, the role of HDL-C associated with developing ischemic stroke exists identically but underestimated. Such finding focused the additive effect implied the equal importance in double helix, then decreasing number of GT repeats act additively with the increasing protective effects, as some previous reports described[39,40].

The limitations of this study should be mentioned. Our study is a case control study. The controls were recruited from outpatients of the same hospital who seemed to have higher levels of several CVD risk factors than general population. On the other hand, although we only included the first case without the history of CAD or stroke to reduce the selection bias, however, we still not avoid the loss in the stroke patients died before admission. Fortunately, the number is few. Taken together, the effect of HO-1 genotype on ischemic stroke may have been underestimated.

\section{Conclusions}

We have demonstrated that the long lengths of (GT) repeats in HO-1 gene promoter are associated with the high risk status on cerebral infarction in subjects with low HDL$\mathrm{C}$ status. The protection form shorter HO-1 gene promoter on stroke may be more critical in patients with lower HDL$\mathrm{C}$ levels than in those with higher HDL-C levels. The findings suggest that genetic characteristics of the HO-1 gene may interact with the oxidative stress conditions to contribute to the development of ischemic stroke. These findings should be confirmed further in population-based studies.

\section{Competing interests}

The authors declare that they have no competing interests.

\begin{abstract}
Authors' contributions
CHB participated in the design of the study, carried out the data collection from interview and lab, performed the statistical analysis, drafted and revised the manuscript. JRC and HCC carried out the screen and enrolment of all patients (cases and controls), particularly by neurological evidences. CCC extracted all of the clinical information, and reconfirmed the diagnosis of chronic diseases such as dyslipidemia. LYC carried out all of the molecular genetic studies. WHP conceived of the study, and participated in its design and coordination. All authors read and approved the final manuscript.
\end{abstract}

\section{Acknowledgements}

This study was supported by grants from Shin Kong WHS Memorial Hospital (SKH-8302-98-NDR-07) and the National Science Council (NSC95-2314-B341002). The greatest appreciation should go to the patients who have been participated this study.

\section{Author Details}

${ }^{1}$ Central Laboratory, Shin Kong WHS Memorial Hospital, Taipei, Taiwan, 2 School of Public Health, Taipei Medical University, Taipei, Taiwan, ${ }^{3}$ Changhua Christian Hospital Yunlin Branch, Yun-Lin County, Taiwan, 4Department of Neurology, Shin Kong WHS Memorial Hospital, Taipei, Taiwan, 5 Department of Internal Medicine, Chang Gung Memorial Hospital, Keelung, Taiwan and ${ }^{6}$ Institutes of Biomedical Sciences, Academia Sinica, Taipei, Taiwan
Received: 1 September 2009 Accepted: 23 February 2010

Published: 23 February 2010

\section{References}

1. Maines MD: Heme oxygenase: function, multiplicity, regulatory mechanisms, and clinical applications. Faseb J 1988, 2:2557-2568.

2. Otterbein LE, Choi AM: Heme oxygenase: colors of defense against cellular stress. Am J Physiol Lung Cell Mol Physiol 2000, 279:L1029-1037.

3. Funk M, Endler G, Schillinger M, Mustafa S, Hsieh K, Exner M, Lalouschek W, Mannhalter C, Wagner $O$ : The effect of a promoter polymorphism in the heme oxygenase-1 gene on the risk of ischaemic cerebrovascular events: the influence of other vascular risk factors. Thromb Res 2004 113:217-223.

4. Kawamura K, Ishikawa K, Wada Y, Kimura S, Matsumoto H, Kohro T, Itabe $\mathrm{H}$, Kodama T, Maruyama Y: Bilirubin from heme oxygenase-1 attenuates vascular endothelial activation and dysfunction. Arterioscler Thromb Vasc Biol 2005, 25:155-160.

5. Kajimura M, Shimoyama M, Tsuyama S, Suzuki T, Kozaki S, Takenaka S, Tsubota K, Oguchi Y, Suematsu M: Visualization of gaseous monoxide reception by soluble guanylate cyclase in the rat retina. Faseb J 2003, 17:506-508.

6. Liu XM, Chapman GB, Peyton KJ, Schafer Al, Durante W: Carbon monoxide inhibits apoptosis in vascular smooth muscle cells. Cardiovasc Res 2002, 55:396-405.

7. Morgan L, Hawe E, Palmen J, Montgomery H, Humphries SE, Kitchen N: Polymorphism of the heme oxygenase- 1 gene and cerebral aneurysms. Br J Neurosurg 2005, 19:317-321.

8. Bergeron M, Ferriero DM, Vreman HJ, Stevenson DK, Sharp FR: Hypoxiaischemia, but not hypoxia alone, induces the expression of heme oxygenase-1 (HSP32) in newborn rat brain. J Cereb Blood Flow Metab 1997, 17:647-658.

9. Geddes JW, Pettigrew LC, Holtz ML, Craddock SD, Maines MD: Permanent focal and transient global cerebral ischemia increase glial and neuronal expression of heme oxygenase-1, but not heme oxygenase2, protein in rat brain. Neurosci Lett 1996, 210:205-208.

10. Beschorner R, Adjodah D, Schwab JM, Mittelbronn M, Pedal I, Mattern R, Schluesener HJ, Meyermann R: Long-term expression of heme oxygenase-1 (HO-1, HSP-32) following focal cerebral infarctions and traumatic brain injury in humans. Acta Neuropathol 2000, 100:377-384

11. Chang EF, Claus CP, Vreman HJ, Wong RJ, Noble-Haeusslein LJ: Heme regulation in traumatic brain injury: relevance to the adult and developing brain. J Cereb Blood Flow Metab 2005, 25:1401-1417.

12. Chen K, Gunter K, Maines MD: Neurons overexpressing heme oxygenase- 1 resist oxidative stress-mediated cell death. J Neurochem 2000, 75:304-313.

13. Le WD, Xie WJ, Appel SH: Protective role of heme oxygenase-1 in oxidative stress-induced neuronal injury. J Neurosci Res 1999, 56:652-658

14. Yachie A, Niida Y, Wada T, Igarashi N, Kaneda H, Toma T, Ohta K, Kasahara Y, Koizumi S: Oxidative stress causes enhanced endothelial cell injury in human heme oxygenase-1 deficiency. J Clin Invest 1999, 103:129-135.

15. Ishikawa K, Maruyama Y: Heme oxygenase as an intrinsic defense system in vascular wall: implication against atherogenesis. J Atheroscler Thromb 2001, 8:63-70.

16. Hoekstra KA, Godin DV, Cheng KM: Protective role of heme oxygenase in the blood vessel wall during atherogenesis. Biochem Cell Biol 2004, 82:351-359.

17. Ishikawa K, Sugawara D, Wang X, Suzuki K, Itabe H, Maruyama Y, Lusis AJ: Heme oxygenase- 1 inhibits atherosclerotic lesion formation in Idlreceptor knockout mice. Circ Res 2001, 88:506-512.

18. Duckers HJ, Boehm M, True AL, Yet SF, San H, Park JL, Clinton Webb R, Lee ME, Nabel GJ, Nabel EG: Heme oxygenase-1 protects against vascular constriction and proliferation. Nat Med 2001, 7:693-698.

19. Juan SH, Lee TS, Tseng KW, Liou JY, Shyue SK, Wu KK, Chau LY: Adenovirus-mediated heme oxygenase-1 gene transfer inhibits the development of atherosclerosis in apolipoprotein E-deficient mice. Circulation 2001, 104:1519-1525.

20. Idriss NK, Blann AD, Lip GY: Hemoxygenase-1 in cardiovascular disease. J Am Coll Cardiol 2008, 52:971-978.

21. Kutty RK, Kutty G, Rodriguez IR, Chader GJ, Wiggert B: Chromosomal localization of the human heme oxygenase genes: heme oxygenase-1 
(HMOX1) maps to chromosome 22q12 and heme oxygenase-2 (HMOX2) maps to chromosome 16p13.3. Genomics 1994, 20:513-516.

22. Lavrovsky Y, Schwartzman ML, Levere RD, Kappas A, Abraham NG: Identification of binding sites for transcription factors NF-kappa B and AP-2 in the promoter region of the human heme oxygenase 1 gene. Proc Natl Acad Sci USA 1994, 91:5987-5991.

23. Yamada N, Yamaya M, Okinaga S, Nakayama K, Sekizawa K, Shibahara S, Sasaki H: Microsatellite polymorphism in the heme oxygenase-1 gene promoter is associated with susceptibility to emphysema. Am J Hum Genet 2000, 66:187-195.

24. Chen YH, Lin SJ, Lin MW, Tsai HL, Kuo SS, Chen JW, Charng MJ, Wu TC, Chen LC, Ding YA, Pan WH, Jou YS, Chau LY: Microsatellite polymorphism in promoter of heme oxygenase-1 gene is associated with susceptibility to coronary artery disease in type 2 diabetic patients. Hum Genet 2002, 111:1-8.

25. Kaneda H, Ohno M, Taguchi J, Togo M, Hashimoto H, Ogasawara K, Aizawa T, Ishizaka N, Nagai R: Heme oxygenase-1 gene promoter polymorphism is associated with coronary artery disease in Japanese patients with coronary risk factors. Arterioscler Thromb Vasc Biol 2002, 22:1680-1685.

26. Schwertner HA, Jackson WG, Tolan G: Association of low serum concentration of bilirubin with increased risk of coronary artery disease. Clin Chem 1994, 40:18-23.

27. Hopkins PN, Wu LL, Hunt SC, James BC, Vincent GM, Williams RR: Higher serum bilirubin is associated with decreased risk for early familial coronary artery disease. Arterioscler Thromb Vasc Biol 1996, 16:250-255.

28. Exner M, Schillinger M, Minar E, Mlekusch W, Schlerka G, Haumer M, Mannhalter $C$, Wagner O: Heme oxygenase-1 gene promoter microsatellite polymorphism is associated with restenosis after percutaneous transluminal angioplasty. J Endovasc Ther 2001 8:433-440.

29. Dick P, Schillinger M, Minar E, Mlekusch W, Amighi J, Sabeti S, Schlager O, Raith M, Endler G, Mannhalter C, Wagner O, Exner M: Haem oxygenase-1 genotype and cardiovascular adverse events in patients with peripheral artery disease. Eur J Clin Invest 2005, 35:731-737.

30. Chalmers J: Global impact of stroke. Heart Dis 2000, 2:S13-17.

31. Carr FJ, McBride MW, Carswell HV, Graham D, Strahorn P, Clark JS, Charchar FJ, Dominiczak AF: Genetic aspects of stroke: human and experimental studies. J Cereb Blood Flow Metab 2002, 22:767-773.

32. Morita T: Heme oxygenase and atherosclerosis. Arterioscler Thromb Vasc Biol 2005, 25:1786-1795.

33. Berg A, Johns J, Baumstark M, Keul J: HDL-cholesterol (HDL-C) changes during and after intensive long-lasting exercise. Int J Sports Med 1981, 2:121-123.

34. Kimpara T, Takeda A, Watanabe K, Itoyama Y, Ikawa S, Watanabe M, Arai H, Sasaki H, Higuchi S, Okita N, Takase S, Saito H, Takahashi K, Shibahara S: Microsatellite polymorphism in the human heme oxygenase-1 gene promoter and its application in association studies with Alzheimer and Parkinson disease. Hum Genet 1997, 100:145-147.

35. Chen YH, Chau LY, Lin MW, Chen LC, Yo MH, Chen JW, Lin SJ: Heme oxygenase-1 gene promotor microsatellite polymorphism is associated with angiographic restenosis after coronary stenting. Eur Heart J 2004, 25:39-47.

36. Ginsberg HN: New perspectives on atherogenesis: role of abnormal triglyceride-rich lipoprotein metabolism. Circulation 2002, 106:2137-2142

37. Nofer JR, Kehrel B, Fobker M, Levkau B, Assmann G, von Eckardstein A: HDL and arteriosclerosis: beyond reverse cholesterol transport. Atherosclerosis 2002, 161:1-16.

38. Maritim AC, Sanders RA, Watkins JB: Diabetes, oxidative stress, and antioxidants: A review. J Biochem Mol Toxicol 2003, 17:24-38.

39. Sheu CC, Zhai R, Wang Z, Gong MN, Tejera P, Chen F, Su L, Thompson BT, Christiani DC: Heme oxygenase-1 microsatellite polymorphism and haplotypes are associated with the development of acute respiratory distress syndrome. Intensive Care Med 2009, 35:1343-1351.

40. Lublinghoff N, Winkler K, Winkelmann BR, Seelhorst U, Wellnitz B, Boehm BO, Marz W, Hoffmann MM: Genetic variants of the promoter of the heme oxygenase-1 gene and their influence on cardiovascular disease (the Ludwigshafen Risk and Cardiovascular Health study). BMCMed Genet 2009, 10:36. doi: 10.1186/1423-0127-17-12

Cite this article as: Bai et al., Shorter GT repeat polymorphism in the heme oxygenase-1 gene promoter has protective effect on ischemic stroke in dyslipidemia patients Journal of Biomedical Science 2010, 17:12

\section{Submit your next manuscript to BioMed Centra and take full advantage of:}

- Convenient online submission

- Thorough peer review

- No space constraints or color figure charges

- Immediate publication on acceptance

- Inclusion in PubMed, CAS, Scopus and Google Scholar

- Research which is freely available for redistribution
C BioMed Central 